University of Wollongong

Research Online

Faculty of Social Sciences - Papers (Archive) Faculty of Arts, Social Sciences \& Humanities

$1-1-2018$

Parental perceptions of barriers to mental health services for young people

Wendy Iskra

University of Wollongong,wi01@uowmail.edu.au

Frank P. Deane

University of Wollongong, fdeane@uow.edu.au

Tim Wahlin

University of Wollongong, twahlin@bigpond.com

Esther Davis

University of Wollongong, eld458@uowmail.edu.au

Follow this and additional works at: https://ro.uow.edu.au/sspapers

Part of the Education Commons, and the Social and Behavioral Sciences Commons

Research Online is the open access institutional repository for the University of Wollongong. For further information contact the UOW Library: research-pubs@uow.edu.au 


\title{
Parental perceptions of barriers to mental health services for young people
}

\begin{abstract}
Aim: This study explores a range of barriers that parents encountered in accessing mental health services. The study also explored whether parents experienced similar barriers to accessing services in 2003 and 2013. Methods: One hundred and thirty-four parents of young people attending an initial assessment at a Child and Adolescent Mental Health Service (CAMHS) or headspace centre completed a questionnaire assessing 10 general barriers to care. These data were compared to those collected from 129 participants at CAMHS in 2003. Results: The ranking of barriers to mental health care for their children was similar for both survey years, with 'wait time being too long' and 'help being too expensive' the two highest ranked barriers. Cost factors were related to not knowing that the services did not charge fees and having to take time off work to attend appointments. Multiple referral steps and uncertain wait times were the main concerns regarding wait times. The overall strength with which barriers were endorsed remained relatively low; however, at least $40 \%$ of the sample agreed they had experienced four of the barriers in both years. Conclusions: Despite relatively low endorsement of barriers, there are substantial proportions of parents who experienced some barriers to services, and services should continue working to reduce them to facilitate timely access. There is a particular need for more servicerelated information to clarify that public sector mental health services do not charge fees. Methods such as rapid initial assessment and actively managing wait lists may go some way to reducing perceived wait time barriers.
\end{abstract}

\section{Keywords}

young, services, health, people, mental, parental, barriers, perceptions

Disciplines

Education | Social and Behavioral Sciences

\section{Publication Details}

Iskra, W., Deane, F. P., Wahlin, T. \& Davis, E. L. (2018). Parental perceptions of barriers to mental health services for young people. Early Intervention in Psychiatry: the development, onset and treatment of emerging mental disorders, 12 125-134. 
Parental perceptions of barriers to mental health services for young people

RUNNING HEAD: Barriers to services for young people

Frank P. Deane

Wendy Iskra

Tim Wahlin

Esther L. Davis

School of Psychology

Illawarra Institute for Mental Health

University of Wollongong

Wollongong NSW 2522

Australia

Corresponding author:

Esther L. Davis

Illawarra Institute for Mental Health (Building 22)

University of Wollongong

Wollongong NSW 2522

Australia

Phone: +612 42215624

Email: eld458@uowmail.edu.au 


\begin{abstract}
Aim: This study explores a range of barriers that parents encountered in accessing mental health services. The study also explored whether parents experienced similar barriers to accessing services in 2003 and 2013.
\end{abstract}

Methods: One hundred and thirty-four parents of young people attending an initial assessment at a Child and Adolescent Mental Health Service (CAMHS) or headspace centre completed a questionnaire assessing 10 general barriers to care. These data were compared to that collected from 129 participants at CAMHS in 2003.

Results: The ranking of barriers to mental health care for their children were similar for both survey years, with the barriers of wait time being too long and help being too expensive were the highest ranked barriers. Cost factors were related to not knowing that the services did not charge fees and having to take time off work to attend appointments. Multiple referral steps and uncertain wait times were the main concerns regarding wait times. The overall strength with which barriers were endorsed remained relatively low, but at least $40 \%$ of the sample agreed they had experienced four of the barriers in both years.

Conclusions: Despite relatively low endorsement of barriers, some are still experienced and services should continue working to reduce them to facilitate timely access. There is a particular need for more service related information to clarify that public sector mental health services do not charge fees. Methods such as rapid initial assessment and actively managing wait lists may go some way to reducing perceived wait time barriers. 
Key words: Parental help seeking, barriers, cost, wait time, mental health. 


\section{Introduction}

Poor mental health and substance use problems affect 10-20\% of children and adolescents worldwide. ${ }^{1}$ In 2000 the Australian National Survey of Mental Health and Wellbeing NSMHWB ${ }^{2}$ reported up to $27 \%$ of adolescents and young adults aged 13 to 24 had a diagnosable mental or substance use disorder. A more recent report in 2012 indicated that this figure has remained relatively constant, with $26 \%$ of adolescents and young adults aged 15 to 19 diagnosed with a mental or substance use disorder and suicide accounting for one in four deaths. ${ }^{3}$ At least one out of every four to five young people across the globe suffer from at least one mental health disorder in any given year. ${ }^{4}$

Despite the prevalence of mental health issues in young people, only $44 \%$ of adolescents and young adults with a mental health problem had accessed a professional service of any type in a 12-month period. ${ }^{5}$ The number of young people in receipt of mental health services is far lower than the level of need, despite the negative repercussions of untreated mental health disorders. ${ }^{6}$

Many mental health disorders begin during adolescence. ${ }^{7}$ Prevention of the progression of mental health disorders should be a primary focus for young people and their caregivers, ${ }^{4}$ and addressing early psychological distress may prevent recurrent or persistent psychopathology through adulthood. Delays in obtaining treatment may contribute to increased risk of morbidity and mortality ${ }^{8-11}$ and poorer long-term outcomes $^{10,12}$ for the young person. Therefore, investigating the factors influencing help 
seeking is of vital importance for improving accessibility of child and adolescent mental health services and to facilitate early intervention strategies and support. ${ }^{8,9,13}$

Parents and other significant adults are often the primary gatekeepers to healthcare for young people and are frequently the first to recognise problems with their children and to initiate the help seeking process. ${ }^{14}$ However, enabling and inhibiting factors operate throughout the help seeking process, and include attitudinal and financial factors, and availability and quality of services. Barriers include negative perceptions of treatment; problems with access to services, such as distance and transportation issues; scheduling and financial issues; and poor client-therapist relationships. ${ }^{15,16}$ These barriers can lead to some parents abandoning or postponing their help seeking efforts. Such delays may persist until the problem escalates and increases the urgency and motivation to obtain help. ${ }^{17}$

Previous research regarding access to mental health services for children has focused broadly on the range of factors that parents have identified as barriers to initiating treatment e.g. ${ }^{15,18}$. In the NSMHWB,${ }^{2}$ the most frequently identified barriers included cost factors, not knowing where to get help, and the wait for help being too long. Many parents reported that their child "did not want help", which is consistent with the view that parental influence is necessary for many young people to reach professional help. ${ }^{2}$ Wahlin ${ }^{19}$ collected data in 2003 to extend the findings of the NSMHWB survey by exploring the barriers parents faced when accessing public mental health services for their children at three Child and Adolescent Mental Health Services (CAMHS) sites. CAMHS are part of a State-wide public sector mental health service which provides 
support to young people with moderate to severe mental health issues. The study reported that parents had endorsed similar barriers to those identified in the NSMHWB survey, with the three highest ranked barriers being "help was too expensive", "the wait for help was too long" and "my child did not want help". However, the need to more fully understand the source of parents concerns about cost and wait time as barriers was also identified.

\section{Objectives}

The first objective of this study is to update the findings by Wahlin ${ }^{19}$ a decade after his data were collected and to further clarify the meaning attributed to the two most commonly reported barriers from the 2003 study: cost of treatment and wait time. The study also examines whether there were differences in the endorsement of barriers by parents seeking help for their children from 2003 to 2013. The second objective was particularly relevant given two significant changes to mental health care provision in Australia that were implemented in 2006: the introduction of the Better Access to Mental Health Care initiative to enable affordable access to Medicare-funded psychological services, ${ }^{20}$ and the development of headspace services funded by the Australian Government, which provide free or low fee medical and early intervention support to young people aged 12-25 years with mild to moderate mental health issues. ${ }^{21}$

\section{Methods}

Participants

Participants were eligible to participate if they were parents/carers of young people who had been referred to the service between 14 and 18 years of age. This age range was 
chosen to match Wahlin's ${ }^{19}$ criteria. Wahlin chose this range because he also had selfreport data provided by the young people themselves and at age 14 they were generally considered able to provide meaningful responses regarding their experiences of the help seeking process (e.g., degree of influence from others). The upper age of 18 years was chosen because the participating CAMHS has this as their upper age limit for referrals. To be eligible, parents also needed to have sufficient English comprehension to understand and complete the study documents and provide informed consent.

The sample comprised of 134 parents or carers (hereinafter referred to as parents) of young people aged between 14 and 18 years of age attending an initial clinical assessment interview during the 6 month period of June 2013 - December 2013 at either CAMHS Illawarra or headspace Wollongong. Fifty-eight questionnaires were obtained from CAMHS Illawarra site and 76 from headspace. This data was compared to 129 participants from CAMHS Illawarra, Ryde and Hornsby sites in 2003. All sites provided no fee services. The questionnaire was completed prior to the initial appointment, usually in the service waiting area.

\section{Measures}

\section{Parent Questionnaire}

The Parent Questionnaire (PQ) consisted of demographic and background information. Ten statements were listed that reflected the barriers parents might confront when seeking mental health care for their children. Wahlin ${ }^{19}$ selected these items based on the most commonly endorsed barriers identified in the NSMHWB. ${ }^{2}$ Parents indicated on a 6-point Likert scale ( $1=$ strongly disagree; $6=$ strongly agree), the extent to which they 
agreed or disagreed that each statement represented a barrier they had encountered in finding help for their child. Examples are: "I thought I could solve my child's problems on my own"; "My child did not want professional help"; and "I thought services were too far away". Parents were also able to describe and rate any other barrier they had encountered which they considered important.

In 2013 the questionnaire was expanded to include five statements for each of the cost and wait barriers that were derived from literature relating to parental barriers to mental health care for their children e.g. ${ }^{22,23,24}$. These items explored a range of factors that might contribute to the cost (e.g. "I had to take time off work") and wait (e.g. "The services I accessed had to refer my child on to another service"). Parents were asked to indicate their agreement with each item using the same 6-point scale used with the other barrier items above. Parents first completed the original items by Wahlin ${ }^{19}$ prior to completing the 10 new items.

\section{Procedure}

Ethical approval for the study was received from the University of Wollongong, Human Research Ethics Committee (HREC); Illawarra Shoalhaven Local Health District HREC Research Governance Office; and approval was provided by the participating headspace lead agency (Illawarra-Shoalhaven Medicare Local).. Research procedures of the study were designed to fit within the standard intake practices of the CAMHS and headspace services. Questionnaires and information sheets were handed directly to parents of children aged 14 to 18 who were attending their first visit at headspace and 
CAMHS Illawarra sites while waiting to be seen. All parents were advised that the questionnaires were anonymous and participation was voluntary.

\section{Results}

Data analysis was conducted using PAWS Statistics SPSS version 18 (SPSS Inc., Chicago IL). There were small amounts of missing data resulting in variation in sample sizes for some analyses. The results for 2003 incorporate CAMHS sites at Hornsby, Ryde and Illawarra, whereas the 2013 results incorporate CAMHS Illawarra and headspace Wollongong. Since some barrier items did not meet the normality assumption, a series of non-parametric tests were conducted. To control for Type-I-error Bonferroni adjustments were made. The adjusted p-values are presented separately for the applicable analyses below.

\section{Participant characteristics and pre-service contacts}

The 2013 sample comprised 134 parents/carers of 89 female (66\%) and 45 male (34\%) young people who attended the initial assessment. The young people had a mean age of 15.2 years $(\mathrm{SD}=1.18)$. In response to an item that asked about the sequence of prior contacts, 32 parents $(25 \%)$ reported that they were the first to notice an issue with their child, followed by school/school counsellor/principal (25\%), and then GP (7.8\%). On average, parents had accessed three contacts or services (including themselves) before they attended the assessment.

Comparisons of sample characteristics of CAMHS and headspace participants revealed no significant differences between the groups on the relationship of carer attending 
(e.g., mother/father/other), child's gender, age, or the proportion who had previously received mental health care (all $\mathrm{p}>.05)$.

Reliable data regarding the response rate of those agreeing or declining to participate was not available but, we are able to provide estimates based on the total number of new referrals to each service during the study period. Reasons for non-participation were unable to be specified but included, declining to participate, the parent/carer not accompanying the young person to their appointment, or the parents not being asked by reception staff to participate. During the study period there were a total of 336 new referrals to the CAMHS service of clients in the 14 to 18 age range. Thus, $17 \%$ of potential participants completed the survey. There were no significant differences in the gender distributions between those who participated (females 66\%, males 34\%) and those who did not participate (females $68 \%$, males $32 \% ; \chi^{2}{ }_{1,336}=0.10, \mathrm{p}>.05$ ). The headspace service was unable to separate out new referrals in the 14-18 year range only, and their summary data included 12 and 13 year olds. There were a total of 235 new referrals during the study period providing a conservative response rate estimation of at least $32 \%$. There were no significant differences in the gender distributions between those who participated (females 65\%, males 35\%) and those who did not participate (females $68 \%$, males $32 \% ; \chi^{2} 1,305=0.17, \mathrm{p}>.05$ ).

Comparison between Illawarra CAMHS and headspace 2013 on 10 general barriers A series of 10 non-parametric Mann-Whitney U tests were conducted to compare the strength of barriers between CAMHS Illawarra and headspace (Bonferroni-adjusted 
$\mathrm{p}<.005)$. There were no significant differences between the endorsement of the 10 general barriers at CAMHS Illawarra and headspace sites.

\section{Comparisons between 2003 and 2013 Barriers to Care}

A series of non-parametric Mann-Whitney U tests were conducted to compare strength of barriers between 2003 and 2013 (Bonferroni-adjusted p<.005). Parental endorsement of the 10 general barriers were not significantly different from 2003 to 2013 (all p>.05, see Table 1).

\section{Relative strength of barriers within year}

Non-parametric Friedman's tests were conducted to determine whether there were differences in the strength of barriers within each year (Bonferroni-adjusted $p<.001$ ). For 2003 responses there was a significant Friedman's test indicating that parents rated some barriers significantly higher than others $\left(\chi^{2} 9,107=178.2, \mathrm{p}<.001\right)$. This analysis is based on mean ranks which are calculated by taking the rank order of each barrier for each participant and dividing through by the number of participants. That is, one item may be ranked $6^{\text {th }}$ by one participant, $5^{\text {th }}$ by another, and $4^{\text {th }}$ by a third person. The mean of these ranks for that item would be 5 (15/3). A series of two-tailed Wilcoxon signedrank tests, (with a significance level of $\mathrm{p}<.01$ ), were performed to investigate the different strengths of each barrier. Mean ranks showed that the parents had rated, "wait for help was too long", "help was too expensive", and "child did not want professional help" as the most highly endorsed barriers (see Table 1). 
A Friedman's test was also significant for the 2013 responses, indicating that parents had rated some barriers significantly higher than others $\left(\chi_{9,134}^{2}=155.13, \mathrm{p}<.001\right)$. A series of two-tailed Wilcoxon signed-rank tests showed the parents had rated "child did not want professional help", "wait for help was too long" and "help was too expensive" had the highest mean ranks. These results were similar to 2003, however the rank order of some of the barriers were different between the years (see Table 1).

\section{Cost and Wait barriers}

The two most commonly reported barriers endorsed in the 2003 study were, "help was too expensive" (cost barrier) and "wait for help was too long" (wait time barrier). In 2013 additional items were developed to try to clarify the content of these barriers further. Tables 2 and 3 provide the means for the five cost items. A Friedman's test indicated there were significant differences in the strength of each cost barrier item overall $\left(\chi_{4,132}^{2}=137.6, p<.01\right)$. A series of two-tailed ( $\left.p<.01\right)$ Wilcoxon signed-rank tests showed the parents from both services rated the cost barriers in the same order, specifically; "did not know there was no fee for the service", "had to take time off work", and "did not have any/enough health insurance" as the most highly endorsed cost barriers.

The mean endorsement of the cost barriers across both CAMHS Illawarra and headspace were in the range of "slightly disagree" or below. However, across both services more $50 \%$ of participants agreed they, "did not know there was no fee" and more than $40 \%$ agreed with the barrier, "had to take time off work". 
A Friedman's test indicated that parents rated the wait time items with different strengths $\left(\chi_{4,131}^{2}=139, p=.02\right)$. Overall, parents rated "the service had to refer my child to another service", "felt my child was so unwell that they needed to be seen sooner", and "family/work schedules had interfered with booking in sessions" as the most highly endorsed wait time barriers. The results are shown in Tables 4 and 5 .

There were significant differences between the two services, with the most highly ranked factor at CAMHS being delays due to having to refer their child to another service. This was followed by not being given any indication of how long they would have to wait, and that they thought their child was so unwell that they need to be seen sooner. Parents at headspace had rated that they thought their child needed to be seen sooner as the most highly endorsed wait time factor. This was followed equally by the wait time being too long and, family/work schedules interfering with the appointments.

As with other barriers overall, the level of agreement for the different wait time barriers was relatively low. The mean level of agreement across both CAMHS Illawarra and headspace were in the range of "slightly disagree" or below. However, there was nearly $40 \%$ agreement for the barrier, "services I accessed had to refer my child on to another service".

\section{Discussion}

The results of this study suggest that there have not been substantial changes to the overall strength or rank order of perceived barriers faced by parents in seeking mental health services for their children. The 10 general barriers were similar in rank order in 
both time periods, indicating that these barriers continue to be of similar importance over time. This is interesting considering the changes to improve affordability and availability of mental health care in Australia in 2006. The most prominent barriers in 2003 were cost, wait time and the child not wanting professional help. In 2013 these were also the highest ranked barriers, although the order had changed, with child not wanting professional help the most strongly endorsed barrier. These findings support other research into barriers to entry into children's mental health services, with similar barriers endorsed by parents including help being too expensive, not knowing where to get help, and long wait for appointments. ${ }^{25}$ The barriers relating to service distance, stigma and thinking treatment would not help were consistently the lowest ranked barriers in both 2003 and 2013 studies.

Notably, the means for each barrier suggest that overall the strength with which barriers were endorsed was relatively low. The range of mean ratings in 2003 was 1.86 to 3.28 and in 2013 the range of mean ratings was 1.99 to 3.16 (scale range 1-6). For several items means were 2 or below, suggesting that on average participants disagreed that these were barriers for them. Specifically, worrying about what people might think if they went to a therapist, thinking treatment would not help, and services being too far away were not considered barriers to services. However, it should be noted that there was some level of agreement (i.e., response of 'Slightly Agree', 'Agree' or 'Strongly Agree') by at least $40 \%$ of respondents for at least four shared barriers in both 2003 and 2013 and an additional barrier specific to each year. Of these, "child did not want professional help", “did not know where to get help", "thought I could solve my child's problems on my own" and "thought the problem would resolve itself over time" all 
reflect issues of mental health literacy. To address these barriers strategies should help provide parents with ways to engage children who might be reluctant to go to treatment. This could include nonthreatening ways to initiate conversations about their problems and how to communicate the need for services as well as information about the types of service. Given many indicated that they did not know where to get help there is a need to continue providing information about available services. Although most parents are likely to try to help a child resolve their problems on their own, helping them recognise the signs that this is not working (e.g., increased severity and persistence of symptoms) may decrease delays in help seeking. The other barriers with substantial agreement were "help was too expensive" and "wait for help was too long", which indicate more service level issues in which there needs to be greater dissemination of accurate information about services and support in accessing them, as discussed further below.

It is somewhat surprising that the ten main barriers to services for CAMHS and headspace services were similar in terms of the strength of endorsement and overall order because they are thought to service different client types and have different service models. CAMHS is targeted at young people with more severe, complex and persistent mental disorders whereas headspace aims to promote and support early intervention for young people. ${ }^{26}$ The lack of differences in perceived barriers between the services may reflect local demands on mental health services where greater need may mean the distinctions in levels of severity may be less. Initial evaluations of headspace suggest that while most young people are experiencing moderate ill health, there is a "substantial subset of young people with more complex, severe and enduring

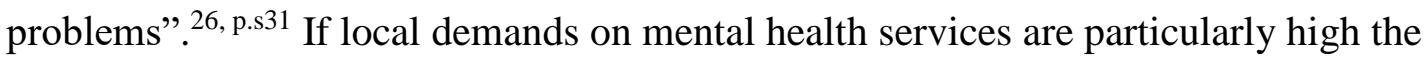


distinction between access and demands may be less apparent. However, further exploration of cost and wait time barriers suggest some differences are present between the services.

Given that in 2003 cost and wait times were the highest ranked barriers, in the 2013 survey, items were added to try and gain a better understanding of what aspects of cost and wait times were of importance to parents. Parents at both CAMHS Illawarra and headspace had ranked cost factors in the same order, with the most influential barrier reported being, "did not know there was 'no fee' for this service". This is surprising as both services are supported by government and other service funding, with no cost to the consumer. There is a need for GPs and other referrers to highlight that both services in this region do not charge a fee. Personnel in schools should also be asked to emphasise this point to parents and headspace centres in particular could take on this responsibility given one of their roles is to deliver community awareness campaigns to facilitate help seeking. ${ }^{26}$ Finally, "Had to take time off work" was the next highest ranked barrier. Both services operate within business hours and so parents may have to allocate time in their work schedule to take their child to the mental health service.

There was greater variability in the rankings for wait time. Overall, the highest ranked barrier related to wait time was having to refer their child to another service. Both CAMHS and headspace conduct triage and assessment, but continuing support from their assessing service is not always certain. Forty-eight percent of parents accessing CAMHS, and $28 \%$ of parents from headspace identified the delay as due to the need for additional referrals from other services. Although the difference between the 
services on this item was not significant, given that CAMHS often work with young people who have severe disorders, it is not surprising that clients have had to be referred from multiple other services or health professionals (e.g. GPs) before gaining access. headspace services have been designed to maximise access and so finding lower rates of delays due to referral processes is encouraging.

The barrier, "was not given any indication of how long I would have to wait", was the second highest barrier endorsed by parents accessing CAMHS, but was the lowest ranked barrier by headspace parents. Wait lists for government supported services can be long e.g. 30 days, ${ }^{27}$, and advising parents of an estimated time can be difficult. Staudt $^{28}$ also found that the most often mentioned barriers to service use were factors at the agency level, such as inconvenient agency hours, scheduling problems and waiting lists.

For the barrier, "wait for help was too long" CAMHS parents had ranked this lowest, while headspace parents ranked this as their third highest barrier. This finding may reflect differences in the wait times for each service, but parents may also react strongly if they feel that their child needs to be seen sooner than available appointments. The need to have their child seen sooner was the highest ranked barrier for headspace parents.

\section{Limitations}

Methodological limitations should be considered when interpreting the findings from this study. Firstly, we were unable to obtain a reliable response rate since on occasion 
potential participants were not provided with a request to participate by service reception staff and these occasions could not be distinguished from those who were invited to participate but then declined. Thus, the representativeness of the sample could not be specified. The sample is drawn from a limited number of treatment settings and does not represent all parents of children with mental health issues. For example, perceived barriers are likely to vary dependent on the location and community context. People living in smaller rural communities where distance and sparse services have been described e.g. ${ }^{29}$ may report quite different barriers to accessing mental health services. Also, we did not collect data regarding young people below age 14 years for whom barriers to help-seeking could be different from those aged 14 and above. The Parent Questionnaire was developed for this study. Although, items were based on findings from the NSHWBS${ }^{2}$ and through a broad range of literature regarding barriers to mental health care, the Parent Questionnaire does not have established reliability and validity data. Finally, the results are specific to parents who actually made it to a service. In this respect the strength of endorsement of barriers are potentially lower than those parents and young people who do not make it to services.

\section{Conclusions}

Despite these limitations the data do suggest that perceived barriers to these mental health services have remained relatively stable over time. While endorsement of the barriers is overall relatively low, there are substantial proportions of parents for which some barriers are present. Concerns about costs of services seem to be mostly a function of not knowing services are free to the user. This finding has direct implications for how services are advertised or promoted, but in particular they highlight the need for those 
professionals early in the help seeking process (e.g. teachers, GPs) to clarify the "no fee" status of these services with parents. Wait time barriers particularly for CAMHS were mostly a function of multiple referral steps whereas for headspace it was more a function of the perceived problem severity increasing the desire for a more immediate response for access. Accessing services may overwhelm some parents if they are new to the mental health system, have had previous trouble accessing services or have a long history of barriers to care and are not yet able to negotiate the system ${ }^{25}$. Accurate information about services, preparation and support for parents to help reduce the impact of potential barriers such as these may reduce unnecessary delays or abandoned attempts to access services. 


\section{Funding}

This research did not receive any specific grant from any funding agency in the public, commercial or not-for-profit sectors.

\section{Declaration of conflicting interest}

The authors report no conflicts of interest. The authors alone are responsible for the content and writing of the paper.

\section{Acknowledgments}

We wish to thank the reception staff at all participating research sites for their support.

In addition, thanks to Carol Martin at the Illawarra Child, Adolescent and Youth Mental Health Service and Peter Murray at headspace Wollongong for providing overall referral rates for these services. 


\section{References}

1. Kieling $\mathrm{C}$, Baker-Henningham $\mathrm{H}$, Belfer $\mathrm{M}$, et al. Child and adolescent mental health worldwide: evidence for action. Lancet. 2011;378:1515-26.

2. Sawyer M, Arney F, Baghurst P, et al. The mental health of young people in Australia: Child and adolescent component of the national survey of mental health and well-being. Aust NZ J Psychiatry. 2000;35(6):806-14.

3. Australian Bureau of Statistics. 3303.0 - Causes of Death, Australia, 2012. Canberra: Australian Bureau of Statistics, 2012 [cited 11 Jan 2015]. Available at: http://www.abs.gov.au/ausstats/abs@.nsf/Lookup/by Subject/3303.0 2012 Main Features Contents $\sim 1$

4. Patel V, Flisher A, Hetrick S, McGorry P. Mental health of young people: a global public-health challenge. Lancet. 2007;369:1302-13.

5. Slade T, Johnston A, Teesson M, et al. The Mental Health of Australians 2. Report on the 2007 National Survey of Mental Health and Wellbeing. Canberra: Department of Health and Ageing, 2009 [cited 15 Dec 2014]. Available at: http://www.health.gov.au/internet/main/publishing.nsf/Content/A24556C814804A99C A257BF0001CAC45/\$File/mha2cov.pdf.

6. Srebnik D, Cauce A, Baydar N. Help-seeking pathways for children and adolescents. J Emot Behav Disord. 1996;4(4):210-20.

7. Australian Institute of Health and Welfare. Australia's Young People. Their Health and Wellbeing. Australian Institute of Health and Welfare, 2003 [cited 12 Jun 2013]. Available at: http://www.aihw.gov.au/publication-detail/?id=6442467534

8. Bailey AP, Parker AG, Colautti LA, Hart LM, Liu P, Hetrick SE. Mapping the evidence for the prevention and treatment of eating disorders in young people. $\mathrm{J}$ Eat Disord. 2014;2:5-.

9. De Silva S, Parker A, Purcell R, Callahan P, Liu P, Hetrick S. Mapping the evidence of prevention and intervention studies for suicidal and self-harming behaviors in young people. Crisis. 2013;34(4):223-32.

10. Johnstone E, Crow T, Johnson A, MacMillan J. The Northwick study of first episodes of schizophrenia. Presentation of the illness and problems relating to admission. Br J Psychiatry. 1986;148:115-20. 
11. Lloyd-Evans B, Sweeney A, Hinton M, et al. Evaluation of a community awareness programme to reduce delays in referrals to early intervention services and enhance early detection of psychosis. BMC Psychiatry. 2015;15:98-.

12. Alvarez-Jimenez M, Gleeson JF, Henry LP, et al. Road to full recovery: Longitudinal relationship between symptomatic remission and psychosocial recovery in first-episode psychosis over 7.5 years. Psychol Med. 2012;42(3):595-606.

13. Sayal K. Annotation: pathway to care for children with mental health problems. J Child Psychol Psychiatry. 2006;47:649-59.

14. Power T, Eiraldi R, Clarke A, Mazzuca L, Krain A. Improving mental health service utilization for children and adolescents. Sch Psychol Q. 2005;20(2):187-205.

15. Kazdin A, Holland L, Cowley M. Family experience of barriers to treatment and premature termination from child therapy. J Consult Clin Psychol. 1997;65(453-463).

16. MacNaughton K, Rodrigue J. Predicting adherence to recommendations by parents of clinic-referred children. J Consult Clin Psychol. 2001;69:262-70.

17. Logan D, King C. Parental facilitation of adolescent mental health service utilization: a conceptual and empirical review. Clin Psychol Sci Pract. 2001;8:319-33.

18. Logan D, King C. Parental identification of depression and mental health service use among depressed adolescents. J Am Acad Child Adolesc Psychiatry. 2002;1:296304.

19. Wahlin T. Parents' and adolescents' perceived influences and barriers to mental health services [Dissertation]. Wollongong: University of Wollongong; 2007 [cited 17 Nov 2012]. Available at: http://ro.uow.edu.au/Thesis/2136/.

20. Whiteford H, Doessel D, Sheridan J. Uptake of Medicare benefits schedule items by psychologists and other mental health practitioners. Clin Psychol. 2008;12(2):50-6.

21. Hodges C, O’Brien M, McGorry P. headspace: national youth mental health foundation: making headway with rural young people and their mental health. Aust $\mathbf{J}$ Rural Health. 2007;15:77-80.

22. Flisher A, Kramer R, Grosser R, et al. Correlates of unmet need for mental health services by children and adolescents. Psychol Med. 2007;27:1145-54.

23. Ensor T, Cooper S. Overcoming barriers to health service access: influencing the demand side. Health Policy Plann. 2004;19(2):69-79. 
24. Thompson A, Issakidis C, Hunt C. Delay to Seek Treatment for Anxiety and Mood Disorders in an Australian Clinical Sample. Behav Change. 2008;25(2):71-84.

25. Owens P, Hoagwood K, Horwitz S, et al. Barriers to children's mental health services. J Am Acad Child Adolesc Psychiatry. 2002;41(6):731-8.

26. McGorry P, Bates T, Birchwood M. Designing youth mental health services for the 21st century: Examples from Australia, Ireland and the UK. Br J Psychiatry Supplement. 2013;54:s30-5.

27. Stokes B. Review of the admission or referral to and the discharge and transfer practices of public mental health facilities/services in Western Australia. Department of Health and Mental Health Commission, Government of Western Australia, 2012. Available at: http://www.mentalhealth.wa.gov.au/Libraries/pdf_docs/Mental_Health_Review_Report by_Professor_Bryant_Stokes_AM_1.sflb.ashx [cited 20 Apr 2014].

28. Staudt M. Barriers and facilitators to use of services following intensive family preservation services. J Behav Health Serv Res. 1999;26:39-49.

29. Aisbett D, Boyd C, Francis K, Newnham K, Newnham K. Understanding barriers to mental health service utilization for adolescents in rural Australia. Rural Remote Health. 2007;7:624. 
Table 1. Means, confidence intervals and mean ranks of perceived barriers for 2003 and 2013.

\begin{tabular}{|c|c|c|c|c|c|c|c|c|c|c|}
\hline \multirow[t]{3}{*}{ Barrier } & \multicolumn{3}{|c|}{$\begin{array}{l}2003 \\
(\mathrm{~N}=107)\end{array}$} & \multicolumn{7}{|c|}{$\begin{array}{l}2013 \\
(\mathrm{~N}=134)\end{array}$} \\
\hline & \multirow[t]{2}{*}{ Mean } & \multirow[t]{2}{*}{ SD } & \multirow[t]{2}{*}{ CI $(95 \%)$} & \multirow{2}{*}{$\begin{array}{l}\text { Mean } \\
\text { Rank }\end{array}$} & \multirow{2}{*}{$\begin{array}{l}\% \\
\text { Agree }^{\dagger}\end{array}$} & \multirow[t]{2}{*}{ Mean } & \multirow[t]{2}{*}{ SD } & \multirow[t]{2}{*}{ CI $(95 \%)$} & \multirow{2}{*}{$\begin{array}{l}\text { Mean } \\
\text { Rank }\end{array}$} & \multirow{2}{*}{$\begin{array}{l}\% \\
\text { Agree }^{\dagger}\end{array}$} \\
\hline & & & & & & & & & & \\
\hline I did not know where to get help & 3.03 & 1.54 & $2.73-3.32$ & $6.29^{\mathrm{abc}}$ & 42.1 & 3.12 & 1.52 & $2.86-3.38$ & $6.34^{\mathrm{a}}$ & 42.7 \\
\hline Health professionals I contacted & 2.29 & 1.37 & $2.03-2.55$ & $4.68^{\mathrm{ef}}$ & 21.7 & 2.42 & 1.37 & $2.19-2.66$ & $4.81^{\mathrm{bfe}}$ & 21.0 \\
\hline \multicolumn{11}{|l|}{ could not assist me to find help } \\
\hline I was worried about what people & 1.99 & 1.20 & $1.76-2.22$ & $4.04^{\mathrm{fg}}$ & 14.1 & 2.10 & 1.31 & $1.88-2.33$ & $4.28^{\mathrm{bce}}$ & 18.9 \\
\hline \multicolumn{11}{|l|}{ would think if I went to a therapist } \\
\hline I thought I could solve my child's & 2.97 & 1.50 & $2.68-3.26$ & $6.30^{\mathrm{abcd}}$ & 42.3 & 2.86 & 1.41 & $2.62-3.10$ & $5.92^{\mathrm{a}}$ & 41.6 \\
\hline
\end{tabular}


problems on my own

\begin{tabular}{|c|c|c|c|c|c|c|c|c|c|c|}
\hline I thought help was too expensive & 3.28 & 1.68 & $2.96-3.60$ & $6.67^{\mathrm{a}}$ & 52.5 & 3.06 & 1.62 & $2.78-3.34$ & $6.35^{\mathrm{a}}$ & 38.6 \\
\hline My child did not want professional & 3.09 & 1.53 & $2.80-3.39$ & $6.50^{\mathrm{ab}}$ & 42.1 & 3.16 & 1.66 & $2.87-3.44$ & $6.41^{\mathrm{a}}$ & 46.1 \\
\hline \multicolumn{11}{|l|}{ help } \\
\hline I thought treatment would not help & 1.86 & 0.92 & $1.68-2.04$ & $3.87^{\mathrm{g}}$ & 9.2 & 1.99 & 1.08 & $1.81-2.18$ & $4.10^{\text {bde }}$ & 14.4 \\
\hline I thought the wait to get & 3.28 & 1.48 & $3.00-3.56$ & $6.72^{\mathrm{a}}$ & 47.0 & 3.12 & 1.57 & $2.85-3.39$ & $6.37^{\mathrm{a}}$ & 44.7 \\
\hline \multicolumn{11}{|l|}{ professional help was too long } \\
\hline I thought the problem would & 2.74 & 1.49 & $2.45-3.03$ & $5.71^{\text {bcde }}$ & 38.0 & 2.89 & 1.52 & $2.64-3.16$ & $6.00^{\mathrm{af}}$ & 42.1 \\
\hline \multicolumn{11}{|l|}{ resolve itself over time } \\
\hline I thought services were too far & 2.02 & 0.95 & $1.84-2.20$ & $4.22^{\mathrm{fg}}$ & 10.7 & 2.12 & 1.20 & $1.92-2.32$ & $4.41^{\mathrm{e}}$ & 14.4 \\
\hline away & & & & & & & & & & \\
\hline
\end{tabular}


Note. Scores ranged from 1-6; higher scores represent greater perceived barrier.

a,b,c,d,e,f,g The mean ranks that differ from each other at $p<.01$ do not share a letter.

† Percent Agree constitutes cumulative ratings of 'slightly agree', 'agree' and 'strongly agree'. 
Table 2. Mean, confidence intervals and mean ranks of cost barriers separately for CAMHS Illawarra and headspace.

\begin{tabular}{|c|c|c|c|c|c|c|c|c|}
\hline \multirow[t]{4}{*}{ Cost Barriers } & \multicolumn{4}{|c|}{ CAMHS Illawarra } & \multicolumn{4}{|c|}{ headspace } \\
\hline & \multicolumn{3}{|l|}{$\mathrm{N}=56$} & \multirow{3}{*}{$\begin{array}{l}\text { Mean } \\
\text { Rank }\end{array}$} & \multicolumn{2}{|l|}{$N=76$} & \multirow{3}{*}{ CI $(95 \%)$} & \multirow{3}{*}{$\begin{array}{l}\text { Mean } \\
\text { Rank }\end{array}$} \\
\hline & Mean & SD & CI $(95 \%)$ & & Mean & SD & & \\
\hline & & & & & & & & \\
\hline I did not know there was no fee for this service & 3.32 & 1.66 & $2.88-3.77$ & $3.62^{\mathrm{ad}}$ & 3.67 & 1.66 & $3.29-4.05$ & $3.71^{\mathrm{ad}}$ \\
\hline I had to take time off work & 3.34 & 1.78 & $2.86-3.82$ & $3.61^{\mathrm{a}}$ & 3.05 & 1.68 & $2.67-3.44$ & $3.38^{\mathrm{a}}$ \\
\hline I didn't have any/ enough health insurance & 2.77 & 1.53 & $2.36-3.18$ & $3.15^{\mathrm{ac}}$ & 3.10 & 1.68 & $2.72-3.49$ & $3.28^{\mathrm{ac}}$ \\
\hline Transport costs were too high & 2.04 & 1.04 & $1.76-2.32$ & $2.45^{\mathrm{b}}$ & 2.10 & 1.10 & $1.85-2.36$ & $2.45^{\mathrm{b}}$ \\
\hline I had to pay to arrange care for other children & 1.70 & 0.71 & $1.51-1.89$ & $2.18^{\mathrm{bc}}$ & 1.81 & 0.83 & $1.63-2.01$ & $2.17^{\mathrm{bc}}$ \\
\hline
\end{tabular}

Note. Scores ranged from 1-6; higher scores represent greater perceived barrier.

a,b,c,d,e The mean ranks that differ from each other at $\mathrm{p}<.01$ do not share a letter. 
Table 3. Overall mean and mean ranks of cost barriers $(N=132)$.

\begin{tabular}{lccccc}
\hline Cost barriers & Mean & SD & CI (95\%) & Mean & \% \\
& & & & Rank & Agree $^{\dagger}$ \\
\hline I did not know there was no fee for this service & 3.52 & 1.66 & $3.24-3.81$ & $3.67^{\text {ad }}$ & 53.3 \\
I had to take time off work & 3.17 & 1.72 & $2.88-3.47$ & $3.48^{\text {a }}$ & 42.5 \\
I didn't have any/ enough health insurance & 2.96 & 1.62 & $2.68-3.24$ & $3.23^{\text {ae }}$ & 35.3 \\
Transport costs were too high & 2.08 & 1.08 & $1.89-2.26$ & $2.45^{\text {b }}$ & 9.6 \\
I had to pay to arrange care for other children & 1.77 & 0.78 & $1.63-1.90$ & $2.17^{\text {c }}$ & 5.1 \\
\hline
\end{tabular}

Note. Scores ranged from 1-6; higher scores represent greater perceived barrier.

a,b,c,d,e The mean ranks that differ from each other at $\mathrm{p}<.01$ do not share a letter.

† Percent Agree constitutes cumulative ratings of 'slightly agree', 'agree' and 'strongly agree'. 
Table 4. Mean, confidence intervals and mean ranks of wait time barriers separately for CAMHS Illawarra and headspace.

\begin{tabular}{|c|c|c|c|c|c|c|c|c|}
\hline \multirow[t]{2}{*}{ Wait Time Barriers } & \multicolumn{4}{|c|}{$\begin{array}{l}\text { CAMHS Illawarra } \\
\mathbf{N}=\mathbf{5 7}\end{array}$} & \multicolumn{4}{|c|}{$\begin{array}{l}\text { headspace } \\
\mathrm{N}=76\end{array}$} \\
\hline & Mean & SD & CI $(95 \%)$ & $\begin{array}{l}\text { Mean } \\
\text { Rank }\end{array}$ & Mean & SD & CI $(95 \%)$ & $\begin{array}{l}\text { Mean } \\
\text { Rank }\end{array}$ \\
\hline $\begin{array}{l}\text { The services I accessed had to refer my } \\
\text { child on to another service }\end{array}$ & 3.35 & 1.67 & $2.91-3.80$ & $3.48^{\text {ade }}$ & 2.75 & 1.64 & $2.38-3.13$ & $2.99^{\mathrm{ab}}$ \\
\hline $\begin{array}{l}\text { I felt that my child was so unwell that } \\
\text { he/she needed to be seen sooner }\end{array}$ & 2.96 & 1.61 & $2.54-3.39$ & $3.07^{\mathrm{ac}}$ & 2.87 & 1.49 & $2.53-3.21$ & $3.24^{\mathrm{bc}}$ \\
\hline $\begin{array}{l}\text { Family/ work schedules had interfered with } \\
\text { booking in sessions }\end{array}$ & 2.86 & 1.64 & $2.42-3.30$ & $2.87^{\text {abe }}$ & 2.75 & 1.47 & $2.41-3.09$ & $3.11^{\mathrm{ab}}$ \\
\hline I was told the service wait time and thought & 2.37 & 1.13 & $2.07-2.67$ & $2.46^{\mathrm{b}}$ & 2.75 & 1.39 & $2.43-3.07$ & $3.11^{\mathrm{b}}$ \\
\hline
\end{tabular}


I was not given any indication of how long I $\quad 3.12 \quad \begin{array}{lllllll}1.46 & 2.73-3.51 & 3.12^{\mathrm{a}} & 2.34 & 1.30 & 2.05-2.64 & 2.55^{\mathrm{a}}\end{array}$ would have to wait for help

Note. Scores ranged from 1-6; higher scores represent greater perceived barrier.

a,b,c,d,e The mean ranks that differ from each other at $\mathrm{p}<.01$ do not share a letter. 
Table 5. Overall mean, confidence intervals and mean ranks of wait time barriers $(N=133)$

\begin{tabular}{|c|c|c|c|c|c|}
\hline \multirow[t]{2}{*}{ Wait Time Barriers } & \multirow[t]{2}{*}{ Mean } & \multirow[t]{2}{*}{ SD } & \multirow[t]{2}{*}{ CI $(95 \%)$} & \multirow{2}{*}{$\begin{array}{l}\text { Mean } \\
\text { Rank }\end{array}$} & \multirow{2}{*}{$\begin{array}{l}\% \\
\text { Agree }\end{array}$} \\
\hline & & & & & \\
\hline The services I accessed had to refer my child on to another service & 3.00 & 1.66 & $2.72-3.30$ & $3.21^{\mathrm{bc}}$ & 39.6 \\
\hline I felt that my child was so unwell that he/she needed to be seen sooner & 2.94 & 1.53 & $2.65-3.17$ & $3.18^{\mathrm{b}}$ & 31.6 \\
\hline Family/ work schedules had interfered with booking in sessions & 2.82 & 1.52 & $2.53-3.06$ & $3.02^{\mathrm{ab}}$ & 34.8 \\
\hline I was told the service wait time and thought it was too long & 2.60 & 1.27 & $2.37-2.81$ & $2.83^{\mathrm{a}}$ & 23.4 \\
\hline I was not given any indication of how long I would have to wait for help & 2.68 & 1.42 & $2.43-2.92$ & $2.77^{a b c}$ & 27.0 \\
\hline
\end{tabular}

Note. Scores ranged from 1-6; higher scores represent greater perceived barrier.

a,b,c,d,e The mean ranks that differ from each other at $\mathrm{p}<.01$ do not share a letter.

† Percent Agree constitutes cumulative ratings of ‘slightly agree', 'agree' and 'strongly agree'. 